\title{
Activated Protein C Reduces the Severity of Compression-Induced Spinal Cord Injury in Rats by Inhibiting Activation of Leukocytes
}

\author{
Yuji Taoka, ${ }^{1,3}$ Kenji Okajima, ${ }^{1}$ Mitsuhiro Uchiba, ${ }^{1}$ Kazunori Murakami, ${ }^{1}$ Naoaki Harada, ${ }^{1}$ Masayoshi Johno, ${ }^{2}$ \\ and Masakuni Naruo ${ }^{3}$ \\ Departments of ${ }^{1}$ Laboratory Medicine and ${ }^{2}$ Dermatology, Kumamoto University School of Medicine, Kumamoto, 860, \\ Japan, and ${ }^{3}$ Naruo Orthopedic Hospital, Kumamoto, 860, Japan
}

\begin{abstract}
Activated protein C (APC), an important inhibitor of the coagulation system, has recently been shown to prevent tissue injury by blocking the activation of leukocytes. To determine whether $\mathrm{APC}$ can also prevent post-traumatic spinal cord injury $(\mathrm{SCl})$, a condition in which leukocytes play an important role, we tested the effects of APC on $\mathrm{SCl}$ induced in rats by compression trauma. Administration of APC, either before or after the induction of $\mathrm{SCl}$, markedly reduced the motor disturbances in these animals. In contrast, neither an inactive derivative of activated factor X (DEGR-Xa), a selective inhibitor of thrombin generation, nor active site-blocked APC (DIP-APC) reduced the motor disturbances. Histological examination revealed that intramedullary hemorrhages, observed $24 \mathrm{hr}$ after trauma, were significantly reduced in the animals administered APC. The increase
\end{abstract}

in the tissue level of tumor necrosis factor- $\alpha$ (TNF- $\alpha$ ) and the accumulation of neutrophils in the damaged segment of the spinal cord were significantly inhibited in the animals that had received $A P C$, but were not inhibited in those administered DIP-APC DEGR- a. The induction of leukocytopenia had the same effe $\mathrm{t}$ as $A \mathrm{C}$, in that it significantly reduced motor dist coanges, is ce levels of TNF- $\alpha$, and neutrophil accumula on the animals subjected to compressive $\mathrm{SCl}$. These rinding sug est that in SCI, APC reduces motor disturbar ce primarh, $y$ reducing the amount of TNF- $\alpha$ at the site of iniury, tho. inhibiting neutrophil accumulation and the resultant damage to ne endothelial cells.

Key words: activated protein C; post-traumatic spinal cord injury leukocytes; motor disturbances; TNF- $\alpha$; neutrophils
Spinal cord injury (SCI) is a serious condition th odu lifelong disabilities (Stover and Fine, 1987). Only mite ther peutic measures are currently available for its trath o Brauen et al., 1990). SCI induced by trauma is a cons uence an initial physical insult that is followed by a progres, ve iury provess that involves various pathochemical events $t$ at lead to issue destruction (Young, 1988; Bracken et al., 190). Therapeutic intervention for SCI should therefore be dire at re deing or alleviating this secondary process. $10 \mathrm{gh}$, echanisms are not fully understood, progressi vasc lar events, such as ischemia/ reperfusion-induced endothe damage, are involved in this process (Demopoulos et al., 1978, Means and Anderson, 1983; Xu et al., 1990; Blight, 1992). We have demonstrated that activated neutrophils are important in inducing the damage to endothelial cells observed in SCI induced by trauma (Taoka et al., 1997a).

Activated protein C (APC) is an important physiological anticoagulant that is generated from protein $\mathrm{C}$ by the action of the thrombin-thrombomodulin complex on the endothelial cells (Walker et al., 1979). APC inactivates factors Va and VIIIa, thereby regulating the coagulation system (Walker et al., 1979; Esmon, 1992). APC is also implicated in the regulation of the inflammatory process by its inhibition of cytokine production by monocytes (Grey et al., 1993, 1994). We demonstrated previously that APC prevents the injury to endothelial cells induced by activated leukocytes, primarily by inhibiting the ability of monocytes to produce tumor necrosis factor- $\alpha$ (TNF- $\alpha$ ) (Murakami et

Received Aug. 8, 1997; revised Nov. 26, 1997; accepted Dec. 2, 1997.

Correspondence should be addressed to Dr. Kenji Okajima, Department of Laboratory Medicine, Kumamoto University School of Medicine, Honjo 1-1-1, Kumamoto 860, Japan.

Copyright $\odot 1998$ Society for Neuroscience $0270-6474 / 98 / 181393-06 \$ 05.00 / 0$ al., 1996, 1997). Because TNF- $\alpha$ is a potent activator of neutrophils (Klebanoff et al., 1986), it is possible that APC may also prevent the secondary effects of trauma-induced SCI by inhibiting neutrophil activation. We therefore evaluated the effects of APC in a rat model of compression-induced SCI.

\section{MATERIALS AND METHODS}

Reagents. APC was obtained from human thrombin-activated protein $\mathrm{C}$ and purified by cation-exchange chromatography as described previously (Katsu-ura et al., 1994). Nitrogen mustard was obtained from Sigma (St. Louis, MO). All other reagents used were of analytical grade.

Preparation of dansyl glutamyl-glycyl-arginyl chloromethyl ketone-treated factor Xa. Factor X, purified from human plasma and activated with Russell's viper venom (Bajaj et al., 1981), was inactivated by incubation with a 20-fold molar excess of dansyl glutamyl-glycyl-arginyl chloromethyl ketone (DEGR) for $30 \mathrm{~min}$ at $25^{\circ} \mathrm{C}$, after which the mixture was subjected to extensive dialysis against a solution containing $20 \mathrm{~mm}$ Tris-HCl, pH 7.4, and $100 \mathrm{~mm} \mathrm{NaCl}$. DEGR-treated factor Xa (DEGR$\mathrm{Xa}$ ) has been shown to selectively inhibit thrombin generation by competing with intact factor $\mathrm{Xa}$ for prothrombinase complex formation (Nesheim et al., 1981).

Preparation of diisopropyl fluorophosphate-treated APC (DIP-APC). APC was inactivated with DIP (Sigma) by incubating APC $(1 \mathrm{mg} / \mathrm{ml})$ with $19 \mathrm{mmol} / 1$ of DIP in PBS, pH 7.4, for $2 \mathrm{hr}$ and dialyzing it extensively against the same buffer (Grey et al., 1994). The effectiveness of inactivation was monitored amidolytically by measuring the rate of hydrolysis of the chromogenic substrate S-2366 (Chromogenix AB, Stockholm, Sweden) at $405 \mathrm{~nm}$. The amount of APC activity remaining was $<1 \%$.

Animal model of spinal cord injury. The study protocol was approved by the Kumamoto University Animal Care and Use Committee. The care and handling of the animals were conducted in accordance with the guidelines of the National Institutes of Health. Under pentobarbital anesthesia (45 mg/kg, i.p.) (Abbott Laboratories, North Chicago, IL), adult pathogen-free male Wistar rats (Nihon SLC, Hamamatsu, Japan), weighing 300-350 gm, were subjected to laminectomy using a surgical airtome at the level of the 12th thoracic vertebra (Th12). Spinal cord 


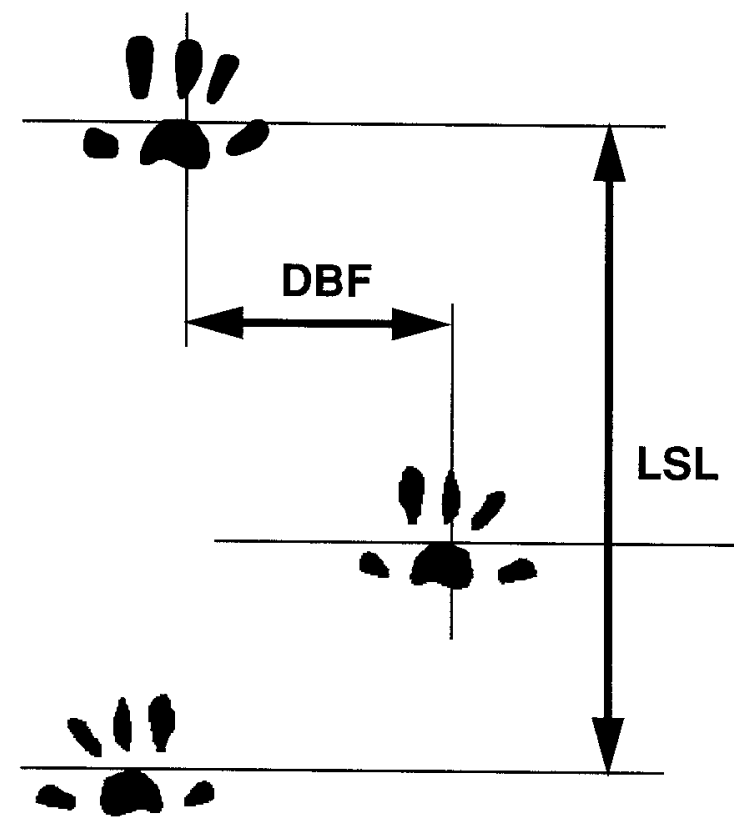

Assay of myeloperoxidase activity. The extent of leukocyte infiltration was assessed by measurement of myeloperoxidase (MPO) activity (Lundberg and Arfors, 1983) using a modification of a method described previously ( $\mathrm{Xu}$ et al., 1990). Within $1 \mathrm{hr}$ after the rats were killed, sections of $\sim 1 \mathrm{~cm}$ were dissected from the Th12 region, removed, and placed in ice-cold $0.9 \% \mathrm{NaCl}$ bath. A $10 \%$ (wt/vol) tissue homogenate was mixed with a $20 \mathrm{~mm}$ phosphate buffer, $\mathrm{pH} 6.0$, containing $0.5 \%$ hexadecyltrimethyl ammonium bromide (Sigma) and sonicated for 30 sec. After centrifugation $\left(4500 \times g\right.$ at $4^{\circ} \mathrm{C}$ for $\left.20 \mathrm{~min}\right), 0.1 \mathrm{ml}$ of supernatant was added to $0.6 \mathrm{ml}$ of $0.1 \mathrm{M}$ phosphate buffer, $\mathrm{pH} 6.0$, containing $1.25 \mathrm{mg} / \mathrm{ml}$ o-dianisidine and $0.05 \% \mathrm{H}_{2} \mathrm{O}_{2}$. After $5 \mathrm{~min}$, the change in absorbance at $460 \mathrm{~nm}$ was measured spectrophotometrically (DU-54, Beckman, Irvine, CA), and the MPO activity in each sample was calculated using a standard curve for purified MPO (Sigma).

Assay of TNF- $\alpha$. The level of TNF- $\alpha$ in spinal cord tissue was determined before and 1, 2, 3, 4, 6, 12, and $24 \mathrm{hr}$ after SCI according to the methods described by Murakami et al. (1997). Briefly, within $1 \mathrm{hr}$ after the rats were killed, sections from the Th12 region measuring $\sim 1 \mathrm{~cm}$ were dissected, removed, and placed in ice-cold $0.9 \% \mathrm{NaCl}$. A $20 \%$ (wt/vol) tissue homogenate was mixed with a $0.1 \mathrm{M}$ phosphate buffer, $\mathrm{pH}$ 7.4 , sonicated for $30 \mathrm{sec}$, and centrifuged at $4500 \times g$ for $20 \mathrm{~min}$ at $4^{\circ} \mathrm{C}$. The concentration of $\mathrm{NF}-\mathrm{n}$ the supernatant was determined using an enzyme-linked imp nosorben assay (ELISA) kit for rat TNF- $\alpha$ (Genzyme Corporation, mbridg MA). Results are expressed as picograms of TN $a$ per gi $\rho^{\prime}$ issue.

Induction of lew cytopewa by nitrogen mustard. Rats were made leukocytop Aic the in avenous injection of nitrogen mustard (NM) (Mül -Bergha an Eckhart, 1975). Because the dose of NM of 1.75 mg $\mathrm{kg}$ a vinistero $\mathrm{m}$ an earlier study had caused death in all rats within $10 \mathrm{~d}$ of la inectomy, probably as a result of infection (Taoka et al., 1997b), we $\mathrm{hm}$ administered an intravenous dose of $1.0 \mathrm{mg} / \mathrm{kg}$. This dose 9 used no deaths for 3 weeks after SCI. NM or $0.9 \% \mathrm{NaCl}$ was admini tered intravenously to rats $2 \mathrm{~d}$ before induction of SCI. The ircu ting leukocyte count on day 0 was $9375 \pm 1365 / \mu l(n=10)$ in controls and $3350 \pm 230 / \mu 1$ in NM-treated rats $(n=10)(p<0.01)$. In ufferential leukocyte counts made on peripheral blood smears, the number of neutrophils counts on day 0 was $1298 \pm 428 / \mu \mathrm{l}$ in controls and $733 \pm 112 / \mu \mathrm{l}$ in NM-treated rats $(p<0.01)$, and the number of monocytes was $539 \pm 286 / \mu \mathrm{l}$ in controls and $182 \pm 38 / \mu \mathrm{l}$ in NM-treated animals $(p<0.01)$.

Statistical analysis. Data are presented as the mean \pm SD. Circulating leukocyte counts were compared using Student's $t$ test. Statistical comparisons of the mean degrees in the inclined-plane test, mean distance between feet, mean stride length, mean MPO activity, and the mean TNF- $\alpha$ level between groups used the ANOVA and Scheffe's post hoc test. A level of $p<0.05$ was defined as statistically significant.

\section{RESULTS}

\section{Effect of APC on $\mathrm{SCl}$ induced by compression trauma}

As reported previously (Hamada et al., 1996), we found that when evaluated by the inclined-plane test, motor disturbances were increased within $24 \mathrm{hr}$ of the compressive SCI. After $24 \mathrm{hr}$, the neurological scores were significantly higher in the rats treated with APC before the induction of SCI versus that of the controls (Figs. 2, 3). From 1 to $21 \mathrm{~d}$ after the induction of SCI, the angle of the inclined plane was significantly higher in the rats pretreated with APC than in the controls (Fig. 2).

The administration of APC after trauma also significantly improved the motor function of rats. Whether evaluated by the inclined-plane test (Figs. 3, 4A) or footprint analysis (Fig. 4B,C), the neurological scores 1 and $21 \mathrm{~d}$ after the induction of SCI were higher in the rats administered APC post-traumatically than in controls.

In contrast to APC, neither DEGR-Xa (a selective inhibitor of thrombin generation) nor DIP-APC (active site-blocked APC) had any effect on the motor function of rats 1 and $21 \mathrm{~d}$ after the injury to the spinal cord (Figs. 3, 4). 


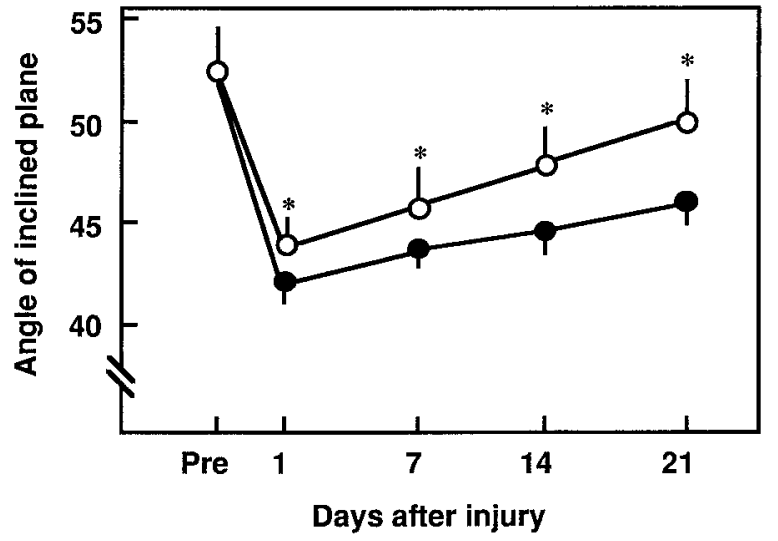

Figure 2. Temporal effect of pretreatment with APC on motor disturbances after compressive SCI. Spinal cord injury was induced by applying a $20 \mathrm{gm}$ weight for $20 \mathrm{~min}$ at Th12, and motor disturbances of the hindlimbs were evaluated after SCI using an inclined-plane test. APC $(100 \mu \mathrm{g} / \mathrm{kg}$ ) or buffer (as a control) was administered intravenously 30 min before injury. Closed circles, Traumatized animals; open circles, APCtreated animals. Mean \pm SD of 10 experiments. ${ }^{*} p<0.01$ versus traumatized animals.

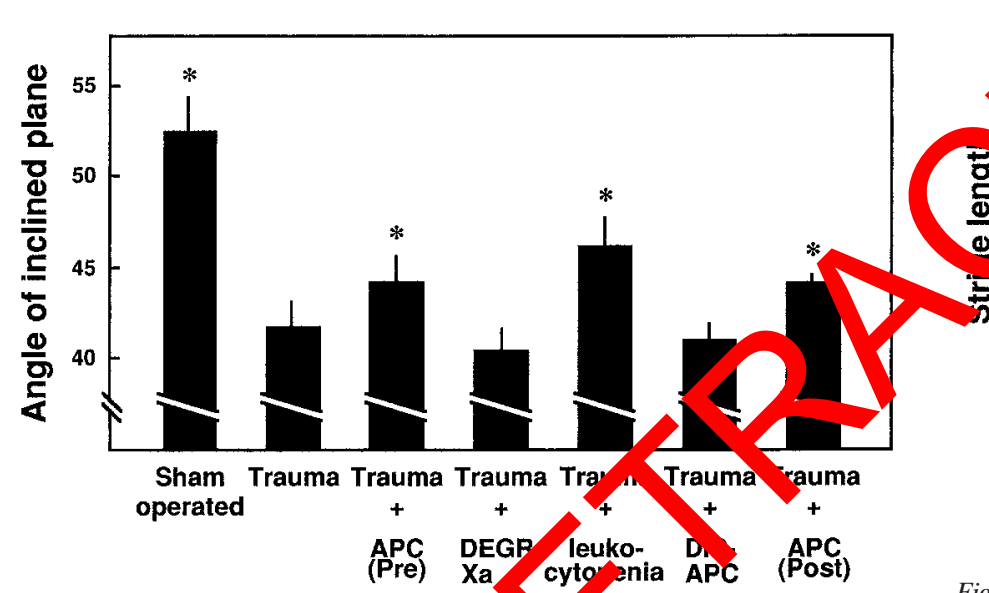

Figure 3. Effects of APC, DEGR - YM- duce leukocytopenia, and DIP-APC on motor disturbance $/ \mathrm{d}$ aft $\mathrm{r}$ ind $\mathrm{n}$ of SCI as determined by an inclined-plane test. Mo di hindlimbs were evaluated $1 \mathrm{~d}$ later using an inclì plane test. APC $(100 \mu \mathrm{g} / \mathrm{kg})$, DIPAPC $(100 \mu \mathrm{g} / \mathrm{kg})$, DEGR-Xa (10 $\mathrm{h} / \mathrm{kg})$, or buffer (as a control) was administered intravenously 30 min berore injury, or APC was administered $30 \mathrm{~min}$ after injury. Leukocytes were depleted by administration of nitrogen mustard $(\mathrm{NM})$. Mean $\pm \mathrm{SD}$ of 10 experiments. ${ }^{*} p<0.05$ versus Trauma.

\section{Histological observations}

Histological examination of the traumatized spinal cord $24 \mathrm{hr}$ after the induction of SCI showed the presence of intramedullary hemorrhages in control animals (Fig. 5). These hemorrhages were observed more often in the gray than in the white matter. In contrast, there was markedly less hemorrhage in the animals that had received APC before trauma (Fig. 5). Neither DEGR-Xa nor DIP-APC prevented hemorrhagic changes in the injured spinal cord (data not shown).

\section{Effect of APC on increase in MPO activity induced by trauma}

The accumulation of neutrophils at the traumatized spinal cord tissue was evaluated by measuring MPO activity $3 \mathrm{hr}$ after the induction of compressive trauma. The increase in MPO activity,
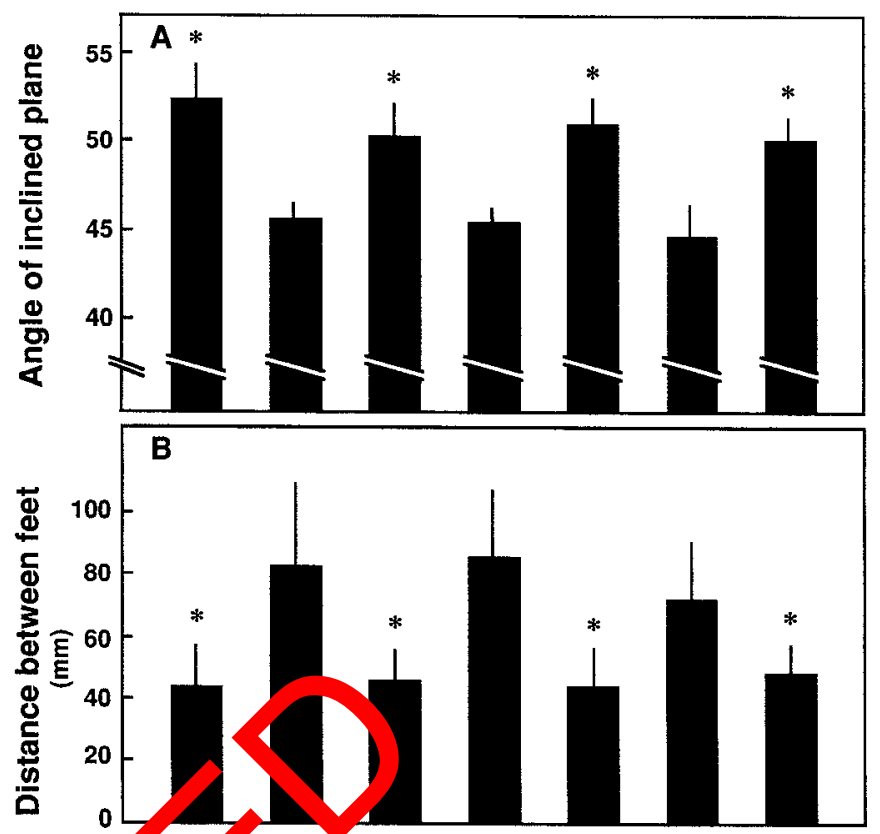

Figure 4. Effects of APC, DEGR-Xa, NM-induced leukocytopenia, and DIP-APC on motor disturbances $21 \mathrm{~d}$ after induction of SCI as determined by an inclined-plane test and footprint analysis. Motor disturbances of the hindlimbs were evaluated $21 \mathrm{~d}$ after induction of SCI using the inclined-plane test and footprint analysis. Concentrations of APC, DEGR-Xa, NM, and DIP-APC were as in Figure 3. Mean \pm SD of 10 experiments. ${ }^{*} p<0.01$ versus Trauma.

observed in traumatized animals versus sham-operated rats, was inhibited significantly in the spinal cord of animals that received APC $30 \mathrm{~min}$ before trauma (Fig. 6 $A$ ). The administration of DEGR-Xa or DIP-APC did not inhibit this increased MPO activity (Fig. 6A).

\section{Effects of APC and nitrogen mustard-induced leukocytopenia on increased TNF- $\alpha$ in injured segment of spinal cord}

After the induction of SCI at Th12, we measured the level of TNF- $\alpha$ in this segment over time. The tissue level of TNF- $\alpha$ increased significantly within $1 \mathrm{hr}$ and peaked at $4 \mathrm{hr}$ (Fig. 7). The tissue level of TNF- $\alpha$ 1-6 hr after trauma significantly exceeded that of sham-operated animals (Fig. 7).

When we evaluated the effect of APC on tissue levels of TNF- $\alpha$ $4 \mathrm{hr}$ after induction of trauma, we found that APC significantly inhibited the compression-induced increases in TNF- $\alpha$ (Fig. 6B). The animals administered nitrogen mustard to induce leukocy- 

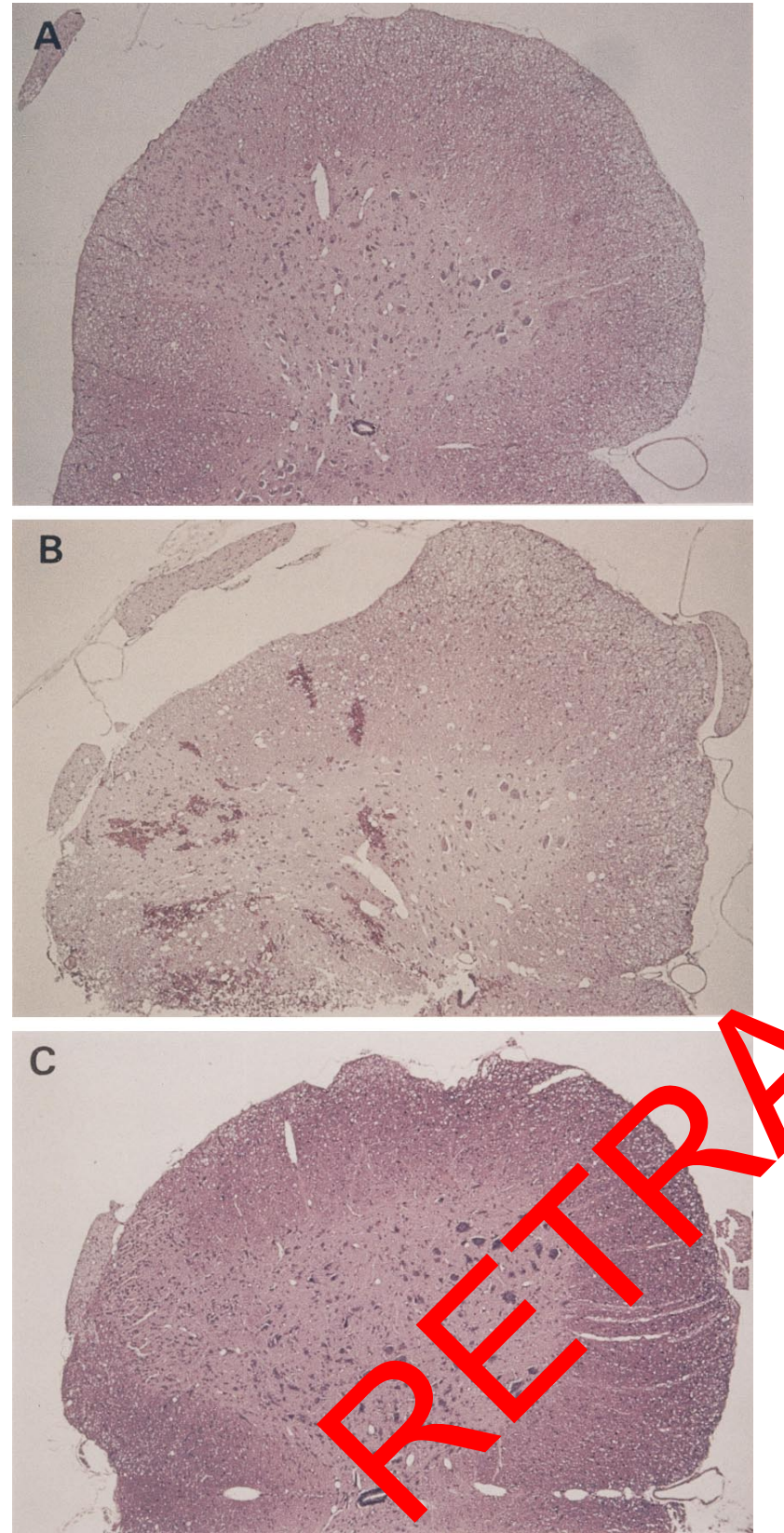

Figure 5. Histology of $(A)$ an intact spinal cord section and in traumatized spinal cord sections from the level of the 12th thoracic vertebra in rats that received $(B)$ saline or $(C)$ APC $(150 \times$, hematoxylin and eosin). Five animals in each group were examined; typical results are shown.

topenia also showed greatly reduced levels of TNF- $\alpha$ (Fig. $6 B$ ). In contrast, neither DEGR-Xa nor DIP-APC had any effect on TNF- $\alpha$ level in animals with SCI (Fig. 6B).

\section{DISCUSSION}

We observed that APC significantly reduced the deleterious effects of SCI in rats. When administered before or after the induction of trauma, APC reduced the number of intramedullary hemorrhages as well as the severity of motor disturbances. Although the motor disturbances evaluated by using the inclinedplane test were not completely recovered $42 \mathrm{~d}$ after trauma, those in animals given APC before or after the trauma were recovered $35 \mathrm{~d}$ after trauma (data not shown), suggesting that APC might

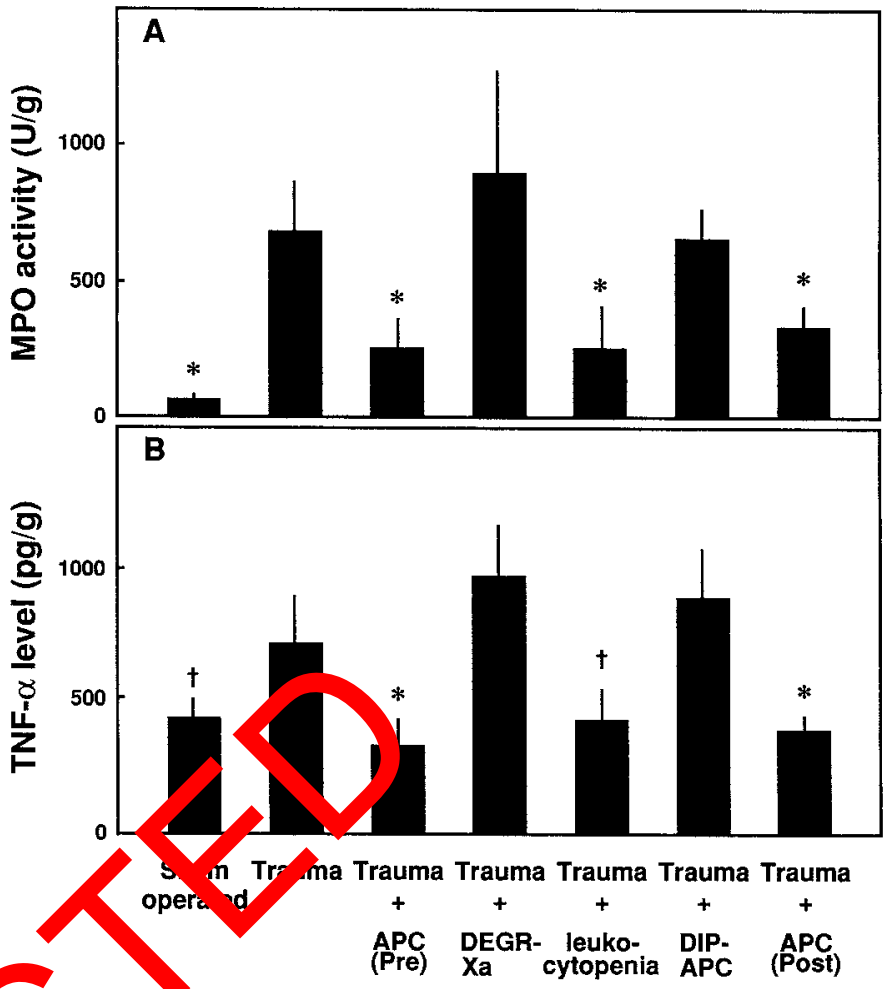

Figure Effects of APC, DEGR-Xa, NM-induced leukocytopenia, and DIP-A $\mathrm{C}$ on $(A) \mathrm{MPO}$ activity and $(B) \mathrm{TNF}-\alpha$ levels in traumatized cord. MPO activity and TNF- $\alpha$ level at Th12 were measured 3 or $4 \mathrm{hr}$ after compressive trauma or a sham-operation, respectively. Mean \pm $\mathrm{SD}$ of five experiments. $t p<0.05$ versus Trauma; ${ }^{*} p<0.01$ versus Trauma.

promote the functional recovery of the motor disturbances in this animal model of spinal cord injury.

Because APC inhibited at the active site (DIP-APC) and a selective inhibitor of thrombin generation (DEGR-Xa) had no effect, our results with APC suggest that the efficacy of this protein may not be mediated by inhibition of thrombin generation. However, this observation does not exclude the possibility that APC may attenuate the spinal cord injury by inactivation of factor $\mathrm{Va} / \mathrm{VIIIa}$.

The accumulation of neutrophils in traumatized segments of the spinal cord as reflected by tissue MPO activity was also significantly inhibited in animals treated with APC. The leukocytopenia induced by NM markedly reduced the motor disturbances as well as accumulation of neutrophils in traumatized spinal cord tissue, suggesting that the accumulation of neutrophils may not be an effect but rather may be a cause of the motor disturbances observed after SCI induced by compression trauma. Because DIP-APC did not prevent the accumulation of neutrophils at the injured site, the inhibition of neutrophil accumulation by APC may also be mediated by its serine protease activity. This is consistent with our previous observation that APC prevents endotoxin-induced lung injury by inhibiting the accumulation of neutrophils, and that this effect is also dependent on the serine protease activity of APC (Murakami et al., 1996, 1997).

Although we observed the accumulation of neutrophils at the traumatized site, we found no histological evidence of their infiltration into the tissue of the injured spinal cord (Taoka et al., 1997a). This suggests that neutrophils may accumulate at the endothelial surface, where they may damage the endothelial cells 


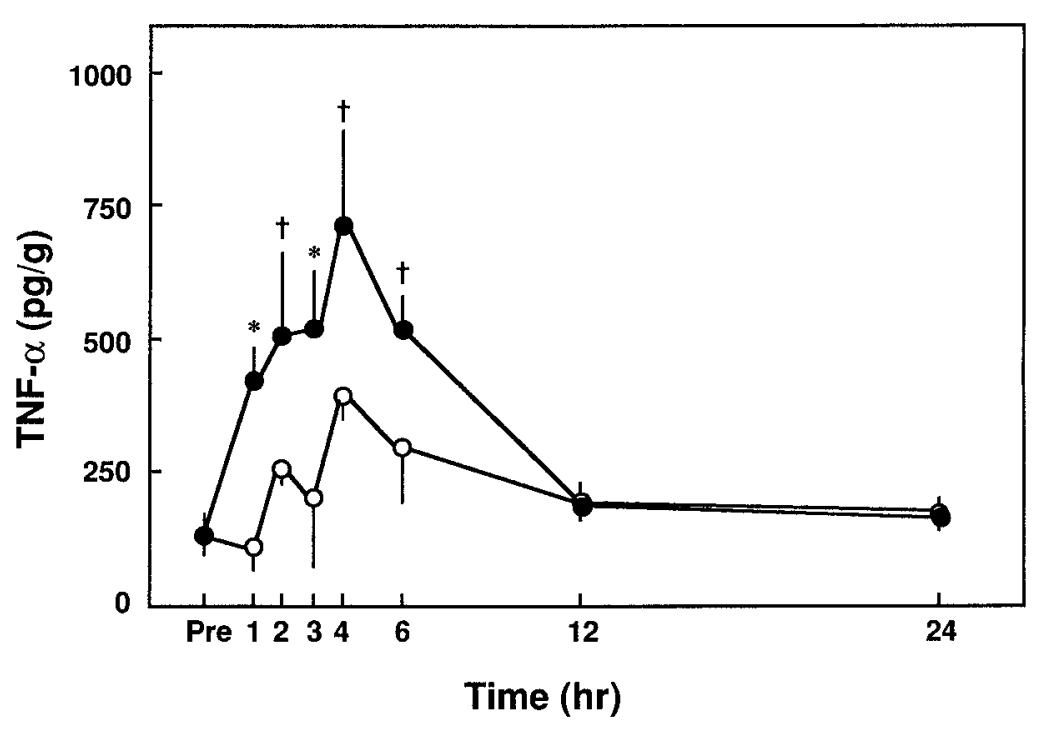

Figure 7. Changes in TNF- $\alpha$ level at Th12 over time after compressive trauma or a sham-operation. TNF- $\alpha$ levels at Th12 were measured before and after the induction of compressive trauma or sham-operation. Closed circles, Traumatized animals; open circles, sham-operated animals. Mean \pm SD of five experiments. $\dagger p<0.05$ versus sham-operated group; * $p<$ 0.01 versus raml gerated group. by releasing a wide variety of inflammatory mediators such as granulocyte elastase and oxygen free radicals (Harlan, 1987; Carlos and Harlan, 1994). Indeed, our preliminary study indicates that L-658,758, a specific granulocyte elastase inhibitor (Zimmerman and Granger, 1990), prevents the SCI induced by compressive trauma in this animal model (our unpublished data).

Our results strongly suggest that the production of TNF- $\alpha$ at the site of SCI is implicated in the secondary damage to tissue in SCI. We found that the level of this protein in the traumatized spinal cord tissue was significantly increased after compre trauma, with a peak seen after $4 \mathrm{hr}$. These results are consis with those of other researchers. For example, Wan showed the presence of TNF- $\alpha$ at the sites of cord lesions but did not detect this factor in cer oros, al fluid or in serum. In addition, Yakovlev and Faden 494) den nstrated that spinal cord impact in rats caused an elev ion of TNF- $\alpha$ mRNA levels at the site of trauma minafter injury; the severity of injury was proportiona to thevel of the TNF- $\alpha$ message. Our additional obseryation, at leu ocytopenic rats in which the level of TNF- $\alpha$ wa not i creas at the site of trauma exhibited a significant reduc on disturbances, indicates that increased levels of TNF- $\alpha$. the site of injury may be a cause, rather than an effect, of the SCI lyced by compressive trauma.

TNF- $\alpha$ contributes to the tissue injury induced by neutrophils by directly activating them (Klebanoff et al., 1986), as well as by increasing the expression of such molecules as E-selectin, which cause the activated neutrophils to adhere to the surface of the endothelial cells (Mulligan et al., 1991). We have also shown that the inhibition of neutrophil adhesion to the endothelial cell surface markedly reduces the severity of the SCI induced by compressive trauma (Taoka et al., 1997a). These observations indicate that the interaction of activated neutrophils with the surface of the endothelial cells is important in the secondary tissue damage that occurs after SCI. Because no increase in the level of TNF- $\alpha$ induced by SCI was found in the animals that had received APC, this suggests that APC may inhibit the accumulation of neutrophils at the site of the traumatic spinal cord injury primarily by inhibiting TNF- $\alpha$ production. This is supported by our earlier findings; i.e., that APC also inhibits the in vivo and in vitro production of TNF- $\alpha$ by monocytes, that this activity depends on the serine protease activity of APC, and that APC does not directly inhibit the neutrophils (Murakami et al., 1997).
Although th pree me nanism(s) by which APC inhibits the production of $\mathrm{TD}^{\mathrm{N}} \mathrm{F}-\alpha$, not been fully elucidated, our finding that DIP-A $Q$ C did nat affect the level of TNF- $\alpha$ at the site of traup sugges the the serine protease activity of APC may be im, orta in tho inhibition of TNF- $\alpha$ production. Grey et al. 1993, 199 also reported that APC suppresses the production of TNF- $\alpha$ by LPS-stimulated monocytes by inhibiting the coupling of LP and CD14, but that DIP-APC did not possess this activity. rast, however, Grinnell et al. (1994) demonstrated that the inhibition of neutrophil accumulation by APC was not related to the serine protease activity of APC, because the carbohydrate moieties of APC reacted more with E-selectin than with the sialyl Lewis $X$ antigen of neutrophils. This possibility, however, seems less likely in vivo, because we found that DIP-APC did not reduce the accumulation of neutrophils at the traumatized site.

We have demonstrated that APC can lessen the severity of the SCI induced by trauma by inhibiting the accumulation of neutrophils and the production of TNF- $\alpha$. Because the administration of APC after the injury was as effective as its administration before injury in preventing the secondary effects of SCI, APC may have a potential for clinical use in alleviating the effects of traumatic compression injury to the spinal cord.

\section{REFERENCES}

Bajaj SP, Rapaport SI, Prodanos CA (1981) A simplified procedure for purification of human prothrombin, factor IX and factor X. Prep Biochem 11:397-412.

Blight AR (1992) Macrophages and inflammatory damage in spinal cord injury. J Neurotrauma 9:S83-S91.

Bracken MB, Shepard MJ, Collins WF, Holord TR, Young W, Baskin DS, Eisenberg HM, Flamm E, Leo-Summers L, Maroon J, Maeshall LF, Perot PL, Piepmeier J, Sonntag KH, Wagner FC, Wilberger JE, Winn HR (1990) A randomized, controlled trial of methylprednisolone or naloxone in the treatment of acute spinal-cord injury. New Engl J Med 322:1405-1411.

Carlos TM, Harlan JM (1994) Leukocyte-endothelial adhesion molecules. Blood 84:2068-2101.

Demopoulos HB, Yoder M, Gutman EG, Seligman ML, Flamm ES, Ransohoff J (1978) The fine structure of endothelial surfaces in the microcirculation of experimentally injured feline spinal cords. Scan Electron Microsc 2:677-680.

Esmon CT (1992) The protein C anticoagulant pathway. Arterioscler Thromb 12:135-145.

Grey S, Hau H, Salem HH, Hancock WW (1993) Selective effects of protein $\mathrm{C}$ on activation of human monocytes by lipopolysaccharide, 
interferon-g, or PMA: modulation of effects on CD11b and CD14 but not CD25 or CD54 induction. Transplant Proc 25:2913-2914.

Grey ST, Tsuchida A, Hau H, Orthner CL, Salem HH, Hancock WW (1994) Selective inhibitory effects of the anticoagulant activated protein $\mathrm{C}$ on the ponses of human mononuclear phagocytes to LPS, IFN-g, or phorbolester. J Immunol 153:3664-3672.

Grinnell BW, Hermann RB, Yan SB (1994) Human protein C inhibits selectin-mediated cell adhesion: role of unique fucosylated oligosaccharide. Glycobiology 4:221-225.

Hamada Y, Ikata T, Katoh S, Nakauchi K, Niwa M, Kawai Y, Fukuzawa K (1996) Involvement of an intracellular adhesion molecule 1-dependent pathway in the pathogenesis of secondary changes after spinal cord injury in rats. J Neurochem 66:1525-1531.

Harlan JM (1987) Consequences of leukocytes-vessel wall interactions in inflammatory and immune reactions. Semin Thromb Hemost 13:425-433.

Katsu-ura Y K, Aoki H, Tanabe M, Funatsu A (1994) Characteristic effects of activated human protein $\mathrm{C}$ on tissue thromboplastin-induced disseminated intravascular coagulation in rabbits. Thromb Res 76:353-357.

Klebanoff SJ, Vadas MA, Harlan JM (1986) Stimulation of neutrophils by tumor necrosis factor. J Immunol 136:4220-4225.

Kunkel-Bagden E, Bregman BS (1993) Methods to assess the development and recovery of locomotor function after spinal cord injury in rats. Exp Neurol 119:153-164.

Lundberg C, Arfors K (1983) Polymorphonuclear leukocyte accumulation in inflammatory dermal sites as measured by $51 \mathrm{Cr}$-labeled cells and myeloperoxidase. Inflammation 7:247-255.

Means ED, Anderson DK (1983) Neuronophagia by leukocytes in experimental spinal cord injury. J Neuropathol Exp Neurol 42:707-719.

Müller-Berghaus G, Eckhart T (1975) The role of granulocytes in the activation of intravascular coagulation and the precipitation of soluble fibrin by endotoxin. Blood 45:631-641.

Mulligan MS, Varani J, Dame MK (1991) Role of endothelial-leukocyte adhesion molecule 1 (ELAM-1) in neutrophil-mediated lung injury in rats. J Clin Invest 88:1396-1406.

Murakami K, Okajima K, Uchiba M, Johno M, Nakagaki T, Okau H, Takatsuki K (1996) Activated protein C attenuates endotovin-ind pulmonary vascular injury by inhibiting activated leuk Blood 87:642-647.
Murakami K, Okajima K, Uchiba M, Johno M, Nakagaki T, Okabe H, Takatsuki K (1997) Activated protein C prevents LPS-induced pulmonary vascular injury by inhibiting cytokine production. Am J Physiol 272:L197-L202.

Nesheim ME, Kettner C, Shaw E, Mann KG (1981) Cofactor dependence of factor $\mathrm{Xa}$ incorporation into the prothrombinase complex. J Biol Chem 256:6537-6540.

Rivlin AS, Tator CH (1977) Objective clinical assessment of motor function after experimental spinal cord injury in the rat. $\mathrm{J}$ Neurosurg 47:577-581.

Stover SL, Fine PR (1987) The epidemiology and economics of spinal cord injury. Paraplegia 24:225-228.

Taoka Y, Naruo M, Koyanabi E, Urakado M, Inoue M (1995) Superoxide radicals play important roles in the pathogenesis of spinal cord injury. Paraplegia 33:450-453.

Taoka Y, Okajima K, Uchiba M, Murakami K, Kushimoto S, Johno M, Naruo M, Okabe H, Takatsuki K (1997a) Role of neutrophils in spinal cord injury in the rat. Neuroscience 79:1177-1182.

Taoka Y, Okajima K, Uchiba M, Murakami K, Kushimoto S, Johno M, Naruo M, Okabe H, Takatsuki K (1997b) Reduction of spinal cord injury by administration of iloprost, a stable prostacyclin analog. J Neurosurg 86:1007-10

Walker FJ, Sexton W, Esmo CT (1979) The inhibition of blood coagulation by tiva 1 prote $\mathrm{C}$ through the selective inactivation of activated for V. Bio hi Biophys Acta 571:333-342.

Wang CX, uttin , Herenrans H, Gybels R (1996) Production of tumor necre fao in spi a cord following traumatic injury in rats. J Neuroi vunol $8 \%, 51,56$.

Xus, Hs CY, Liu TH, Hogan EL, Perot E, Tai H (1990) Leukotriene 34 releas and polymorphonuclear cell infiltration in spinal cord injury. J Neurochem 55:907-912.

Yakov v AG, Faden AI (1994) Sequential expression of c-fos protoon ogene, TNF-alpha, and dynorphin genes in spinal cord followexperimental traumatic injury. Mol Chem Neuropathol 23:179-190.

Young W (1988) Secondary CNS injury. J Neurotrauma 5:219-221.

Zimmerman BJ, Granger DN (1990) Reperfusion-induced leukocyte infiltration: role of elastase. Am J Physiol 259:H390-H394. 